\title{
EL HOMENAJE DE UNA CARTA Y DE UN SERMÓN
}

\author{
Juan Alberto Osorio Torres*
}

\section{RESUMEN:}

Este es un artículo contextualizado de teología pastoral en relación con su comprensión antropológica, partiendo de la conmemoración de los tres primeros lustros con una nueva identidad colectiva de comunidad eclesial de la fundación de una parroquia en los arenales del Sur de Lima bajo el cuidado de los sacerdotes de Maryknoll. Este hecho es comparado por el autor con el 'Sermón de Montesinos', pronunciado al final de la primera década del siglo XVI, teniendo en común que son episodios o expresiones simbólicas de un único y siempre vigente proceso: el de institucionalización de la Iglesia, por medio de la localización de sus diócesis; afirmándose que las implicancias pastorales de instalación y funcionamiento de una comunidad eclesial, tienen siempre un carácter profético y evangélico.

PALABRAS CLAVE: Sermón de Montesinos, Iglesia local, Comunidad eclesial, fuerza profética, Diócesis de Lurín.

\section{TRIBUTE TO A LETTER AND A SERMON}

\begin{abstract}
This is a contextualized article of Pastoral Theology in relation to its anthropology comprehension, since the commemoration of the three first diocesan lustra with a new ecclesiastical community collective identity and the foundation of a parish in the sandy area of the south of Lima by Maryknoll priests. This fact is compared by the author with "Montesinos's Sermon", pronounced at the end of the first decade of the XVI century, taking into account that those are episodes or symbolic expressions of a unique and always valid process, the institutionalization of the Church, through their dioceses. The pastoral implications of an ecclesiastic community installment and functioning have always an evangelic and prophetic character.
\end{abstract}

KEYWORDS: Montesinos's Sermon, local Church, ecclesiastic community, prophetic strength, Diocese of Lurin.

*Sacerdote de la Diócesis de Cajamarca, prestando sus servicios a la Diócesis de Lurín en Lima. Magíster en Antropología y candidato a Doctor en esta especialidad en la Pontificia Universidad Católica del Perú. Miembro del Seminario Interdisciplinar de Estudios Religiosos (SIER) de la PUCP. Profesor de Teología y Capellán de la UNIFÉ. Actual Vicario de la Parroquia Sagrado Corazón de Pamplona Alta, responsable parroquial de los Asentamientos Humanos de la Nueva Rinconada de Pamplona. 
El año 2011 está cosechando hitos sumamente valiosos para el mundo, y de modo singular, para los pobladores del Sur de la metrópoli del Perú. Particularmente, porque la conmemoración de los tres primeros lustros diocesanos de su nueva identidad colectiva (1996-2011), trae entre otros acontecimientos de nivel continental, la memoria de los quinientos años de creación de las primeras diócesis en América (1511), en cuyo fundacional contexto destaca la importancia enorme de un famoso sermón. Y porque, para la gente del triple mundo urbano del mar, del valle y sobre todo de los arenales del Sur de Lima, sus bodas diocesanas de cristal coinciden con el centenario de la fundación de Maryknoll, (1911-2011), aquella gran familia religiosa americana, a la que pertenecen los misioneros y misioneras que se hicieron cargo pastoral de la primera parroquia que la Arquidiócesis de Lima aceptó fundar años después de la invasión de Ciudad de Dios (Nochebuena de 1954), en los inaccesibles desiertos de Atocongo (1958). Y en la que, bajo responsabilidad pastoral de Maryknoll, sus laicos redactaron y dirigieron una insólita carta abierta al Presidente de la República, con motivo de otra invasión u ocupación poblacional aún mayor.

Como es obvio, cada uno de estos hechos, habiendo incidido profundamente en su respectivo contexto, con el tiempo perderían trascendencia, de no hacer el esfuerzo por releer, aunque fuese por separado, lo que cada uno dejó sentado ayer, y que hoy continúan representando. Por eso es que, no obstante, aunque se trate de hechos de verdad ajenos, apartados y diferentes, en este artículo aplico la clave que los anuda y reanuda, para rendir homenaje al centenario Maryknoll, por algunos motivos. Porque, la experiencia y la satisfacción de la familia misionera Maryknoll, está profundamente ligada a la riqueza permanente que esta carta representa para el porvenir de la diócesis de Lurín; por lo que por medio de su acción misionera en el mundo, en el Perú y particularmente desde antes que naciera la actual diócesis de Lurín, Maryknoll consiguió poner en marcha y aún puede estar haciendo latir en lo que hay en común, entre aquella antigua y primordial homilía y aquella casi olvidada carta parroquial; porque, esta fiesta es la ocasión genial para burlar los procesos de fragmentación y ocultamiento con que suele filtrarse la amnesia histórica y sus afanes por evitar entrecruzar el vigor de lo ocurrido, tanto en el tiempo como en el espacio.

Paso a mostrar y contextualizar brevemente el sermón de los frailes y la

\footnotetext{
${ }^{4}$ Las festividades por el sermón de Antonio de Montesinos, han sido precedidas un año antes por un Congreso Internacional dedicado a la comunidad a la que pertenecieron él y sus autores en el "Un acontecimiento que cambió el mundo" 20-22 setiembre 2010 http://www.cchs.csic.es/es/node/275172 Para actualizar el vigor profético de la Conferencia de Medellín, la Conferencia de Puebla trajo a la memoria el testimonio de Montesinos y su emblemático sermón (DP 8). Y la de Santo Domingo por doble vez, cuando transcribió el mensaje de Juan Pablo II a los indígenas (SD 4). En Aparecida, extrañamente su nombre no figura, aunque Bartolomé de Las Casas es aludido, y el Papa actual no lo menciona aún entre sus escritos.

${ }^{5}$ La Familia Maryknoll fue homenajeada a nivel nacional, en diciembre 2008, por la Coordinadora Nacional de Derechos Humanos, tras haber efectuado una misión que dejó imborrable huella en el Sur Andino.
} 
carta de los laicos; aplico una perspectiva de la antropología de la religión para mostrar la articulación que existe entre ambos discursos; y concluyo, desprendiendo algunas deudas y perspectivas urgentes que brotan de la conexión de ambos hechos, de sus contenidos y de sus respectivos gestos.

\section{Los documentos y los hechos}

El sermón de Montesinos, fue pronunciado al final de la primera década del siglo XVI, cuando el imperio español pasaba aún por una euforia sin precedentes tras la Reconquista y el descubrimiento del Nuevo Mundo, mientras desde la Isla La Española, arrancaba irreversiblemente el funcionamiento de las primeras diócesis en América. La carta abierta al Presidente de la República de Perú, fue redactada, firmada y divulgada por los agentes pastorales de la parroquia El Niño Jesús de Ciudad de Dios, desde los suburbios de Lima, cuando el gobierno militar de las FFAA, no transcurría aún ni la mitad de su primer quinquenio, y cuando el país bordeaba la segunda mitad del siglo XX, en el caldeado contexto de sucesivas oleadas migratorias.

Más allá del valor histórico de ambos por separado, ¿de qué manera la conjunción de estos hechos aplaude y disfruta de este homenaje a Maryknoll, porque su centenario actualiza la significación de la carta y del sermón?

a) E1 sermón de Montesinos Bartolomé de Las Casas, primero como laico colonizador, luego como cura encomendero, fue testigo y protagonista, mensaje y mensajero de todo el revuelo que produjo este sermón, cuando a sus oradores les correspondió establecer en qué había empezado a consistir el funcionamiento pastoral de la primera diócesis americana. El texto de la homilía, creado por misioneros españoles, y pronunciado en 1511 para solidarizarse con la población indígena, fue además formulado para reivindicar la identidad misionera de la Iglesia, para acreditar el único modelo evangelizador español, y deslindarlo del complaciente, del encubridor y cómplice de la Encomienda; el único que podía preciarse de digno y humano para los seres humanos de ese lugar y de esa época, según la percepción misionera de esta comunidad dominica. Fue una homilía pronunciada por Antonio de Montesinos, un miembro de la comunidad de frailes dominicos, en el contexto de la celebración eucarística y dentro del tiempo litúrgico del Adviento, ante una feligresía perpleja, sobreindignada, encabezada por el hijo de Cristóbal Colón. Dejemos que el propio testigo lo describa y exponga con sus propios términos:

"Llegado el domingo y la hora de predicar, subió en el pulpito el susodicho padre fray Antón Montesinos, y tomó por tema y fundamento de su sermón, que ya llevaba escrito y firmado de los demás: Ego vox clamantis in deserto. Hecha su introducción y dicho algo de lo que tocaba a la materia del tiempo del Adviento, comenzó a encarecer la

${ }^{6}$ J.L. Mora Mérida Misión e institucionalización de la Iglesia en América, Vol. III, p. 739, en Sotomayor (2003).

7 "En consecuencia, las relaciones entre la Iglesia y el Estado, al menos hasta que se inició la conquista del Imperio azteca, sufrieron y pasaron por frecuentes conflictos, que no empañaron a una Iglesia que quiso ser, en el mejor y más amplio sentido de la palabra eminentemente misionera." José Luis Mora Mérida Misión e institucionalización de la Iglesia en América, Vol. III, p. 739, en Sotomayor (2003). 
esterilidad del desierto de las conciencias de los españoles desta isla y la ceguedad en que vivían; con cuánto peligro andaban de su condenación, no advirtiendo los pecados gravísimos en que con tanta insensibilidad estaban continuamente zabullidos y en ellos morían. Luego torna sobre su tema, diciendo así:

"Para os lo dar a conocer me he subido aquí, yo que soy voz de Cristo en el desierto desta isla, y por tanto, conviene que con atención, no cualquiera, sino con todo vuestro corazón y con todos vuestros sentidos, la oigáis; la cual os será la más nueva que nunca oísteis, la más ásperay dura y más espantable y peligrosa que jamás no pensasteis oír.» Esta voz encareció por buen rato con palabras muy pungitivas y terribles, que les hacía estremecer las carnes y que les parecía que ya estaban en el divino juicio. La voz, pues en gran manera, en universal encarecida, declaróles cuál era o qué contenía en sí aquella voz: «Esta voz, dijo él, es que todos estáis en pecado mortaly en él vivis y morís, por la crueldad y tiranía que usáis con estas inocentes gentes. Decid, ¿con qué derecho y con qué justicia tenéis en tan cruel y horrible servidumbre aquestos indios? ¿Con qué autoridad habéis becho tan detestables guerras a estas gentes que estaban en sus tierras mansas y pacificas, donde tan infinitas dellas, con muertes y estragos nunca oídos, habéis consumido? ¿Cómo los tenéis tan opresos y fatigados, sin darles de comer ni curarlos en sus enfermedades, que de los excesivos trabajos que les dais incurren y se os mueren, y por mejor decir, los matáis, por sacar y adquirir oro cada dia? ¿Y qué cuidado tenéis de quien los doctrine, y conozcan a su Dios y criador, sean bautizados, oigan misa, guarden las fiestas y domingos?» «¿Estos, no son hombres? ¿No tienen ánimas racionales? ¿No sois obligados a amarlos como a vosotros mismos? ¿Esto no entendéis? ¿Esto no sentís? ¿Cómo estáis en tanta profundidad de sueño tan letárgico dormidos? Tened por cierto que en el estado que estáis no os podéis más salvar que los moros o turcos que carecen y no quieren la fe de Jesucristo.»

Finalmente, de tal manera explicó la voz que antes había muy encarecido, que los dejó atónitos, a muchos como fuera de sentido, a otros más empedernidos y algunos algo compungidos, pero a ninguno, a lo que yo después entendí, convertido."

Como describe Codina (2011), el impacto del sermón fue grande. Diego Colón y los notables salieron indignados y decidieron reprender al predicador por aquella doctrina nueva y escandalosa que iba contra el rey, que era quien autorizaba a los conquistadores el tener indios en las encomiendas a su servicio. Exigían una pública retractación. También Bartolomé de Las Casas se indignó con aquel sermón que atacaba directamente su situación de encomendero. Sólo años más tarde, reflexionando sobre textos del Eclesiástico (4,1-6; 34,18-22) que afirman que Yahvé no acepta las ofrendas manchadas con sangre, Las Casas cambió de rumbo, ingresó en la Orden dominicana y nombrado obispo de Chiapas,' se convirtió en el gran defensor de los indígenas.

${ }^{8}$ Las Casas, Bartolomé de, (1986) Historia de las Indias, Libro III p. 13.

${ }^{9}$ El año 2011, la actual Diócesis San Cristóbal de Las Casas de Chiapas, despidió al querido Monseñor Samuel Ruiz García (1924-2011), uno de los contemporáneos sucesores de Bartolomé de Las Casas. 
Al domingo siguiente, Montesinos subió de nuevo al púlpito y en lugar de retractarse dijo que en adelante no confesarían a los españoles, ni les darían la absolución, y recalcó que podían quejarse ante quien quisieran, pero ellos seguirían predicando el evangelio que el funcionamiento solidario, crítico y público de la diócesis, había comenzado. La noticia llegó a la corte española, el superior Pedro de Córdoba fue llamado a declarar ante el rey Fernando el Católico de Castilla, el mismo provincial de los dominicos Alonso de Loaysa se puso de parte del rey y del gobernador de La Española, se enojó, reprendió a sus hermanos por tan escandalosa predicación, perjudicial a su orden. Sin duda se han dejado engañar por el demonio y les manda que nadie siga con este tipo de predicaciones, bajo pena de incurrir en pecado grave y en excomunión.

\section{b) La carta del Consejo Pastoral parroquial de Ciudad de Dios}

Esta carta, dirigida al Presidente de la República en mayo de 1971, fue redactada por la comunidad cristiana de la parroquia El Niño Jesús de Ciudad de Dios, y firmada por los laicos Manuel Ruiz, Bernardino Panana, y por el Padre Carmelo La Mazza, misionero Maryknoll. Ciudad de Dios había nacido 17 años antes con este nombre, durante la nochebuena de 1954, a la intemperie de los desiertos de Atocongo y de una multitudinaria 'invasión'. Y esa carta fue la prueba terminante de cuánto venía madurando la comunidad creyente, tanto en su fe como en su conciencia ciudadana, gracias al acompañamiento fiel de los misioneros y misioneras de Maryknoll. A partir de 1960, el padre William McCarthy y el padre Jaime Madden, y poco tiempo después, las hermanas Catarina Carden, especializada en Catequesis, y María José Toohig, Asistenta Social, fueron los primeros Maryknoll que pusieron las bases fundamentales de ese acompañamiento pastoral de la población. ${ }^{10}$ Uno de los frutos de aquella primera década de esfuerzos pastorales, lo fue esta carta ${ }^{11}$ que surgió, a consecuencia de una de las 'invasiones' más espectaculares del país.

El miércoles 5 de mayo de 1971, el Consejo Parroquial dio a conocer esta carta en la que en nombre de su identidad cristiana laical se solidariza y protesta de manera pública, por el desalojo violento y el saldo de un muerto y 50 heridos, entre policías y pobladores.12

El sábado 8 de mayo, los tres firmantes quedaron incomunicados, y tras haberse realizado el domingo la Misa concertada, el lunes 10 Monseñor Bambarén fue acusado por los medios, y la carta del Consejo fue calificada de insultante para con el Presidente. Monseñor Bambarén fue detenido también, y solo a las 11de la noche salió en libertad con orden de comparecencia. En medio de protestas por la detención de Monseñor Bambarén, el martes 11 el Juez deja en libertad a los tres firmantes, el Cardenal Juan Landázuri retorna de Costa Rica y expresa su más enérgica protesta por lo

10 Madden, Jaime (2003) Biografía del P. William McCarthy, Misionero Maryknoll, primer párroco de Ciudad de Dios.

11 CEP (1971) Pamplona: más allá de los hechos, p.5.

12 Ibid, Presentación y crónica. 
CARTA DEL PADRE LA MAZZA Y MIEMBROS DEL CONSEJO PARROQUIAL DE CIUDAD DE DIOS CON MOTIVO DE LA INVASION DE PAMPLONA

SEÑOR PRESIDENTE DE LAREPUBLICA

CIUDAD

S.P.

El Consejo Parroquial de Ciudad de Dios del Distrito de San Juan de Miraflores (Conformado por pobladores y representantes de la Parroquia de nuestra localidad).

Elevamos nuestra enérgica protesta frente a los hechos acaecidos en el día 4 y 5 de los corrientes a horas 4:00 a.m.; protagonizados por los miembros de la Guardia Civil; ocasionando víctimas entre muertos y heridos; quienes no han respetado la dignidad humana de hombres, mujeres, ancianos y niños indefensos ni el derecho inalienable de la existencia por el mero hecho de haberse producido una invasión en terrenos eriazos y por demás accidentados.

Frente a estos hechos irrespetuosos a los principios que propugna el Gobierno Revolucionario de las FF.AA. y a la esperanza de que cristianamente sabrá comprender el resultado moral y material ocasionado a estas personas de situación precaria y exiguos recursos económicos.

Por todas estas iniquidades realizaremos una Misa en honor a los caídos e invitamos a todas las Parroquias que congregan a los cristianos ya toda persona que quiera identificarse con nuestro dolor humano; que se realizará el día domingo 9 de los corrientes en el lugar de los hechos y que nos concentraremos en el Puente Atocongo en acceso a la avenida Pachacutec a horas 8:00 a.m.

San Juan de Miraflores, 5 de mayo de 1971

Sr. Bernardino Panana Secretario
R.P. Carmelo La Mazza, M.M

Asesor

Sr Manuel Ruiz C.

Presidente

ocurrido ante cientos de personas en el aeropuerto. Entre el jueves 13 y el viernes 14, con disposición del Ministerio de Vivienda, nace en estas condiciones la nueva urbanización popular Villa El Salvador. ${ }^{13}$

Entre numerosas declaraciones de protesta por los hechos ocurridos, el 13 de mayo, la Arquidiócesis de Lima publica un importante comunicado en el que el Cardenal, los Obispos Auxiliares y los sacerdotes de su Consejo Presbiteral, exponen la relación de los hechos desde la primera invasión y una reflexión pastoral a partir del problema surgido. Es de destacar que en el siguiente párrafo, puede evidenciarse el propósito asumido por los pastores, de darle al funcionamiento pastoral de la Arquidiócesis -iy de todas las diócesis del Perú!- un enrumbamiento distinto, independiente del Estado y distante de la oligarquía local.
"El gesto de Monseñor Bambarén, del párroco Carmelo La Mazza y los directivos de su Consejo Parroquial, señores Manuel Ruiz y Bernardino Panana, constituye un esfuerzo por aplicar concretamente lo que la $36^{\mathrm{a}}$ Asamblea Episcopal Peruana declaró en 1969: "En nuestra (sic) Diócesis denunciaremos enérgicamente los abusos y las injustas consecuencias de las desigualdades excesivas entre ricos y pobres, entre poderosos y débiles, acompañando tales denuncias, si fuera necesario, con gestos concretos de solidaridad para con los pobres y oprimidos". Por eso nos solidarizamos con este gesto y sobre todo con la angustia y el clamor de cuantos carecen de un techo y de un hogar. Estimamos que la dramática situación de estos hermanos es la causa profunda de los acontecimientos que todo lamentamos. Nadie escapa -los cristianos tampoco- a la responsabilidad de este estado de cosas." 15

13 Ibid, Presentación y crónica.

El texto según consta en la XXXVI Asamblea Episcopal, en los siguientes términos: "2.4.6. En nuestras diócesis denunciaremos "enérgicamente los abusos y las injustas consecuencias de las desigualdades excesivas entre ricos y pobres, entre poderosos y débiles (MEDELLIN, Pobreza de la Iglesia, 11,211), acompañando tales denuncias, si fuera necesario, con gestos concretos de solidaridad para con los pobres y oprimidos." Subrayo el plural nuestras diócesis, del texto original, que se distingue del singularizado nuestra diócesis del Comunicado del Arzobispado, por tratarse de un detalle que evidencia el alcance nacional que cobró en el país la transformación del funcionamiento pastoral de la diócesis y en el que se mantuvo comprometida la Iglesia en el Perú.

15 CEP Pamplona: más allá de los hechos. Documentos, p.29. 


\section{E1 sermón y la carta: gestos y contextos de un mismo proceso}

El sermón de Montesinos, del siglo XVI, y la carta de la parroquia Maryknoll, del siglo XX, son episodios o expresiones simbólicas de un único y aún vigente proceso: el proceso de institucionalización de la Iglesia, por medio de la localización de sus diócesis. Ambos comparten casi una misma situación. Y en las dos, se busca hacer prevalecer casi lo mismo. El sermón, pertenece a los albores fundacionales del cristianismo en América. La carta, corresponde a la expansión de la frontera arquidiocesana de Lima y al nacimiento del Cono Sur de la metrópoli, durante un tiempo de profunda renovación de la Iglesia en Perú y el mundo.

Lo que revela el sermón, es que -pese a toda oposición y rechazo- la dimensión y el cometido profundamente pastoral que explica la necesidad de establecer diócesis en el mundo, consiguió ser enarbolada y reivindicada plenamente desde el principio, por quienes decidieron hacerlo públicamente, desde ese momento y ese lugar. La carta parroquial al Presidente, refleja el despertar misionero, y el dinamismo profético y autónomo en que se mostró comprometida públicamente la Arquidiócesis de Lima, tras el impacto que produjera en la Iglesia, el oleaje migratorio en el país, primero con la invasión de Ciudad de Dios (1954), y de modo particular, a raíz de la invasión de Pamplona (1971).

El sermón de Montesinos, forma parte del proceso de instalación de las primeras diócesis. No, del proceso que
Constantino emprendió en el viejo mundo, procurando legalizar el heredado sistema de Diocleciano, -el que diocesinizó el imperio para neutralizar los primeros discípulos misioneros de Jesús-; sino del que, con la misma impronta imperial, fue reanudado eufóricamente en América, por los Reyes Católicos, por Alejandro VI, el Papa del Descubrimiento y por Julio II, el Papa del Patronato y de la instauración de la jerarquía diocesana en Indias. (De la Hera 1995:594).

Para una perspectiva de la antropología de la diócesis, y su propósito de reflexionar sobre las implicancias pastorales de su instalación y funcionamiento, el sermón de Montesinos, constituiría un referente simbólico emblemático, el punto de partida histórico y teológico crucial del proceso de institucionalización del cristianismo católico en el nuevo mundo, por medio de la instalación de las primeras diócesis en nuestro hemisferio. El texto, el gesto y el mismo contexto, son la prueba perdurable que muestra ostensiblemente el sello genuinamente profético y evangélico con que la diócesis fue trasplantada fuera del viejo mundo. El testimonio patente de un gesto misionero que le restituyó autonomía al funcionamiento de la diócesis, que salvaguardó su primacía pastoral por encima de presiones, ventajas y connivencias administrativas. El gesto que desplegó el sentido crítico del Evangelio. El que, sin declinar a su identidad étnica hispana, por mostrarse en su frágil y vulnerable condición humana de misionero, jamás les llevó a renunciar a la majestad de su independencia, convocando a la ternura política de los lazos solidarios con la población 
oriunda y desposeída, anticipando en milenios la hoy tan echada de menos obligatoria interculturalidad del cooperador o misionero extranjero.

La carta parroquial de Ciudad de Dios, por su parte, es la expresión ya no solo de la búsqueda de nuevos caminos pastorales. Ella es una muestra de la audaz respuesta pastoral con que la Arquidiócesis de Lima y la Conferencia Episcopal del Perú, decidieron abandonar, de la Colonia a la República, su anterior funcionamiento diocesano subordinado al Estado y a la oligarquía local. Esa atrevida misiva abierta al Presidente de la República, se convirtió en la ocasión para evidenciar que en el país, a partir de la segunda mitad del siglo $\mathrm{XX}$, la Iglesia católica emprendió un nuevo funcionamiento pastoral de la diócesis. Y que ello era expresado en su apuesta por una profunda renovación bajo el liderazgo del segundo cardenal arzobispo Juan Landázuri Ricketts, en el marco del Concilio Vaticano II, de la Populorum Progressio y de la Conferencia de Medellín. "El cardenal", fue el pastor que lideró un importante proceso de apertura de la Iglesia en el país y fuera de él.

Lo comenzó entre las barriadas del Cono Sur, con la creación de la parroquia El Niño Jesús de Ciudad de Dios, y lo completó dos años después, con el envío de la familia Maryknoll a hacerse cargo de la misma (1960-1985). Esta carta al Presidente de la República, firmada por los laicos Manuel y Bernardino y su párroco Carmelo, es la expresión de una comunidad cristiana adulta, que aunque sus líderes sufrieron prisión, su preparación y madurez le permitió responder de manera solidaria, crítica y pública, a los incidentes de la invasión de Pamplona, en mayo de 1971.

La comunidad de Antonio de Montesinos logró no solo defender y salvaguardar sino, sobre todo, rescatar y restituir al proceso de institucionalización de la Iglesia Católica, el funcionamiento pastoral auténtico de la primera diócesis americana, aunque sufriendo la soledad y la descalificación de propios y ajenos. La carta de la parroquia Niño Jesús de Ciudad de Dios, resultó fortaleciendo el funcionamiento pastoral de la Arquidiócesis, en continuidad con el compromiso que la invasión de Ciudad de Dios llegó a despertar en el Arzobispado de Lima, hizo andar en el Sur de Lima, e indirectamente, en el resto del país.

En otros términos, desde la perspectiva de una antropología de la diócesis, tanto el sermón como la carta, respondieron al triple parámetro en que suele basarse el funcionamiento de toda diócesis o iglesia particular. Tanto en la carta como en el sermón, se verifica la imagen pública, expresada por la estrecha unión entre pastores y fieles, hacia la persona de los sectores más desfavorecidos de la Iglesia local. La falta de apoyo y de reconocimiento de las autoridades políticas y religiosas hacia el sermón de Montesinos, lejos de invalidarlo muestra aún más soberana y digna la contribución de los misioneros dominicos al proceso fundante del enrumbamiento correcto de las primeras diócesis de América. 


\section{De algunas deudas y más de un desafío}

El próximo 3 de diciembre de 2014, el país va a recordar el centenario de una tragedia horrible que resistieron los pobladores llaucanos y llaucanas de Bambamarca.' A raíz de mi trabajo parroquial en aquella zona de la actual diócesis de Cajamarca, durante la década de los ochenta, tuve la oportunidad de visitar frecuentemente a LLaucán y enterarme de esta masacre campesina; incluso de participar en las Honras Fúnebres organizadas por la población para orar por todos los que perdieron la vida en esta ocasión. Al preguntarle acerca de la reacción de la parroquia cercana ante esta matanza, ocurrida setenta años atrás, recuerdo aun lo que me respondió una sobreviviente de aquel 'atraso', la ancianita, Doña Goyita Pereyra, hoy ya fallecida:

- "Y en esos tiempos, el párroco de Bambamarca,... ¿no había párroco en Bambamarca?

- ¡Cómo no!

- ¿qué hizo el padre? ¿No vino a verles?

- Nada, nada!..

- En esos tiempos todo era muy dormido, padrecito! (intervino otro señor anciano)... en ese tiempo había masacres, había abusos. Nadie decía nada.... Nadie.
- Se hacía su ofensa así, y se quedaba en nada...

- El que tenía plata, entonces se creía más hombre y entonceshacía lo que él quería. Y nadie decía nada! Ni las autoridades, ni el párroco, nada! ¡Nadie, padre!

- ¿Dónde habrá estado Dios en ese momento en que llegaron los guardias y le hicieron daño a tantos llaucanitos, doña Goyita?

- ¡Dios, pues, les daría licencia a que venga tanta matanza que hicieron!"17

Este dramático testimonio interpela a respondernos con urgencia en este momento, ¿cómo están funcionando pastoralmente las diócesis en el mundo? ¿Cuál es la imagen pública que el mundo tiene ahora de ellas? ¿Cómo funcionaron en el Perú a partir de la República y durante el régimen de hacienda? ¿Cómo lo hicieron durante los años del conflicto armado? Y hoy, en este tiempo de ininterrumpido crecimiento económico, ¿cómo la ven funcionando los fieles donde el territorio cuenta con recursos hídricos y auríferos? O, donde como en las de Carabayllo, Chosica y Lurín, los niños y los jóvenes, no pueden disfrutar de la comunicación con la madre o el padre y viceversa, por la permanente ausencia de los mismos, obligados a traer dinero con cuanto empleo encuentren?

\footnotetext{
16 "En 1914, Benel obtuvo la locación dela rica hacienda LLaucán de Bambamarca. Sin embargo, los campesinos de dicha hacienda se organizaron con el fin de impedir su ingreso. (...)Buscó la ayuda del Prefecto de Cajamarca, quien se presentó con ochenta gendarmes. Cuando el caballo que el Prefecto montaba recibió un disparo, éste ordenó a la policía que abriera fuego. Algunos informes dicen que los campesinos muertos llegaron a trescientos. La masacre de LLaucán fue un escándalo nacional y fue una de las causas para la fundación de la Sociedad Pro-indígena en 1916. "(Gitlitz 1980:138)

17 Entrevista en LLaucán a doña Goyita Pereyra, 25 julio 1984. Todo lo que se sabe acerca de la reacción del párroco y del obispo ante estos graves hechos, lo refiere Víctor Campos, en su historia: "Tanta fue la maldad de esa matanza que el párroco de Bambamarca, don Edmundo R. Guevara Salinas, le escribió al Obispo de Cajamarca, diciéndole que la Capilla de LLaucán está desconsagrada por haberse derramado sangre sobre ella, lo que explica que los asesinados han sido atacados hasta en los lugares más sagrados, la capilla se encontró repleta de muertos."(1992:217)
} 
Pero además, ¿de qué manera nuestras diócesis peruanas fortalecen y replican el proyecto que perennizó aquel antiguo sermón, y que hace 40 años, con madurez y cordura, al estilo Maryknoll, Ciudad de Dios encarnó en esa carta? ¿En qué medida nuestras diócesis están en condiciones de seguir produciendo comunidades de hombres y mujeres, como la de los misioneros y la de Ciudad de Dios, capaces de brindar solidaridad real y efectiva con quienes hoy, en cualquiera de ellas, ocupan el lugar de los abandonados llaucanos?

En definitiva, el Sermón de Montesinos sigue inspirando y siendo fuente de autonomía y de solidaridad entre los pastores y fieles de nuestras diócesis andinas, amazónicas y altiplánicas y sus áreas urbano marginales. $\mathrm{Al}$ celebrar el centenario de Maryknoll y los primeros quince años del nacimiento de la Diócesis de Lurín, agradecemos profundamente a Dios y a nuestros misioneros y misioneras, particularmente de Maryknoll, porque la comunidad cristiana adulta y laical, solidaria, crítica y pública que forjaron en Ciudad de Dios, rindió fruto 40 años atrás con la famosa carta al presidente de la República; fue y sigue siendo la prueba de su contribución, 500 años después del Sermón de Montesinos.
La carta de la parroquia El Niño Jesús de Ciudad de Dios, a cargo de los misioneros y misioneras de Maryknoll, firmada y publicada hace cuarenta años y releída desde la perspectiva del impacto que produjo y continúa provocando el Sermón de Montesinos, sigue al parecer cumpliendo el objetivo que la originó: advertir y evidenciar que, desde la colonización de América, donde estuvo y continúa estando ayer y hoy, la clave del funcionamiento pastoral de una diócesis, es en el estrecho entendimiento y evangélica comunión entre los pastores y los fieles más abandonados y más indefensos de una iglesia particular.

Porque la diócesis que se instaló en América, no nació funcionando pastoralmente mal. Y que así, aunque al precio de la hostilización, la descalificación y de la misma cárcel, los misioneros dominicos la pusieron en marcha desde la invadida Isla La Española en el Adviento de 1511. Del mismo modo, todo el Cono Sur, hoy convertido en Diócesis de Lurín, ha tenido el privilegio no sólo de ver y oír acerca de este nuevo funcionamiento pastoral de la Arquidiócesis de Lima, sino que tuvo la responsabilidad de haberlo forjado y de estarlo protagonizando desde la comunidad cristiana solidaria, crítica y pública, preparada y animada en Ciudad de Dios y sus alrededores, por la familia Maryknoll. 


\section{Referencias}

- CEP (1971). Pamplona: más allá de los hechos. Documentos. Lima: Centro de Estudios y publicaciones.

- Campos Briceño, Víctor (1992). Historia de Bambamarca, Tomo I. Cajamarca: Grupo Cultural Quiliche, Parroquia Bambamarca.

- Codina, Víctor SJ, (2011). El grito de Montesinos, ayer y hoy. México: Publicación original: Christus 786 (octubre 2011) 18-21.

- Frades, Eduardo C.M.F (1997). El uso de la Biblia en los escritos de Fray Bartolomé de Las Casas. Colección Santa Rosa de Lima No2 (Caracas-Venezuela) Editado por: Instituto Universitario Seminario interdiocesano Santa Rosa de Lima.

- Gitlitz, John (1980). Conflictos políticos en la Sierra Norte del Perú: La montonera Benel contra Leguía, 1924, en Estudios Andinos 16, revista semestral de ciencias sociales en la Región Andina - Año IX N ${ }^{\circ}$ 16.

Hera Pérez-Cuesta, Alberto de la. (1995). Las primeras diócesis americanas Memoria del X Congreso del Instituto Internacional de Historia del Derecho Indiano, ISBN 968-36-4260-8, pp. 587-602

- Las Casas, Bartolomé de (1986). Historia de las Indias. Biblioteca Ayacucho.

- Madden, Jaime (2003). Biografía del P. William McCarthy, Misionero Maryknoll, primer párroco de Ciudad de Dios.

- Martínez, Felicísimo OP (2011). El sermón de Montesinos (comunidad, predicación y defensa de la justicia)

- Sotomayor Manuel y Fernández Ubiña, José coordinadores (2003). Historia del Cristianismo. Vol. I, II, III. España: Editorial Trotta. 